* Doutorando em Direito pela Universidade Federal do Pará (UFPA).

Mestre em Direito em 2015 pela Universidade Federal do Pará (UFPA).

Graduado em Direito em 2012 pela Universidade Federal do Pará (UFPA).

Email: alexandrebonna@ yahoo.com.br

** Doutora em Direito em 2001 pela Pontifícia Universidade Católica de São Paulo (PUC - SP).

Mestre em Direito em 1998 pela Universidade Federal do Pará (UFPA).

Especialista em Direito Civil em 1997 pela Universidade da Amazônia (UNAMA).

Graduada em Direito em 1985 pela Universidade Federal do Pará (UFPA).

Email: pastoraleal@uol.com. br

\section{Requisitos ObJetivos e SubJetivos dos Punitive Damages: Crítérios à Aplicação no Direito Brasileiro}

Objective and Subjective Requirements of Punitive Damages: Criteria For ITS APPLICATION IN BRAZILIAN LAW

\section{Alexandre Pereira Bonna* Pastora do Socorro Teixeira Leal**}

Como citar: BONNA, Alexandre Pereira; LEAL, Pastora do Socorro Teixeira. Requisitos objetivos e subjetivos dos punitive damages: critérios à aplicação no direito brasileiro. Scientia Iuris, Londrina, v. 22, n. 1, p.190-222, mar. 2018. DOI: $10.5433 / 2178-8189.2018 v 22$ n1p190. ISSN: 2178-8189.

Resumo: Realiza pesquisa que parte do pressuposto de que os punitive damages têm cabimento no ordenamento jurídico brasileiro. Procura os requisitos objetivos e subjetivos dos punitive damages na experiência jurídica norte-americana como base para auxiliar a prática jurídica brasileira. Traça o perfil de aplicação dos punitive damages nos Estados Unidos e no Brasil. Busca identificar elementos débeis na prática jurídica pátria. Reflete sobre o incremento na prevenção de danos (principal função dos punitive damages) que os requisitos objetivos e subjetivos dos punitive damages 
podem provocar no caso brasileiro.

Palavras-chave: Responsabilidade civil. Punitive damages. Prevenção de danos. Requisitos dos punitive damages.

Abstract: This study bases itself on the assumption that "punitive damages" exist in the Brazilian legal system. For that reason, this paper investigates the objective and subjective requirements of punitive damages in the United States' as a means for exploring its use in the Brazilian legal experience. Furthermore, this research examines the application of punitive damages in the United States and Brazil, seeking to identify problems in the Brazilian legal system. In conclusion, this body of work explores the use of damage prevention (primary function of punitive damages) and the objective and subjective requirements of "punitive damages" in Brazil.

Keywords: Civil responsibility. Punitive damages. Damage prevention. Requirements of punitive damages.

\section{INTRODUÇÃO}


Os punitive damages são uma categoria jurídica alocada no campo das funções da responsabilidade civil, especialmente na interface das funções preventiva e punitiva ${ }^{1}$, visando a, por meio da fixação de um valor indenizatório maior do que o suficiente para reparar ou compensar o prejuízo sofrido, desestimular a conduta grave e danosa do ofensor.

A doutrina dos punitive damages, apesar de alguns autores vislumbrarem a sua origem no Código de Hammurabi (2000 anos A.C), na Bíblia $^{2}$ e no Direito Romano ${ }^{3}$, é no Direito Inglês que a expressão foi cunhada pela primeira vez no caso Huckle v. Money, em 1973, e no Direito norte-americano que se desenvolveu de forma mais aprofundada, a partir do século XX, em decorrência do crescimento demográfico e do incremento da industrialização.

A experiência norte-americana na aplicação dos punitive damages sofre influência do seu federalismo, marcado por intensa autonomia política, legislativa e administrativa dos Estados, fruto do processo de transformação de Confederação em Federação que culminou

1 São para esses danos, considerados mais graves por algumas características, que a função punitiva da responsabilidade civil se revela adequada, estabelecendo-se aqui o contraponto com a função reparatória, que atua voltada para o dano e não para a gravidade da conduta que o provocou. Assim, ganhou força a função punitiva da responsabilidade civil, visando a punir o agente que cometeu danos a partir de condutas altamente reprováveis. Dentre as várias justificativas para a aplicação da função punitiva a que mais se destaca é a de prevenção de danos, motivo pelo qual se afirma que ambas caminham juntas e cumprem escopos reciprocamente complementares, de modo que o viés de punir por meio de valor indenizatório além do necessário para compensar o dano promove até certo ponto a dissuasão das condutas reprimidas, contribuindo para a sua cessação e não incidência.

2 "The doctrine of punitive damages has an ancient lineage. The Babylonian Hammurabi Code, Hindu Code of Manu, and the Bible, all contain precursors to the modem remedy of punitive damages." (RUSTAD; KOENIG, 1993, p. 1285, tradução nossa): "A doutrina dos punitive damages tem origem antiga. O Código de Hammurabi, O Código Hindu de Manu, e a Bíblia, todos contém elementos do punitive damages."

3 "The laws of the XII Tables declared that whoever should do a personal injury to another should pay twenty-five asses, a considerable sum at the time. At a later time, however, when money abounded, this penalty became so insignificant that one Lucius Veratius used to amuse himself by striking those whom he met in the streets in the face, and then tendering them the legal amends, from a wallet which a slave carried after him for the purpose." (RUSTAD; KOENIG, 1993, p. 1269, tradução nossa): "A lei das XII Tábuas declarava que quem causasse uma injúria a outrem deveria pagar uma soma significativa de dinheiro, que com o passar do tempo se tornou pouco relevante para pessoas com muitos bens em momentos de abundância. Foi o caso de Lucius Veratius, que usava o 'preço do ilícito' para se divertir atacando pessoas no rosto oferecendo em seguida o correlato pagamento." 
na formação dos Estados Unidos da América ${ }^{4}$, motivo pelo qual há 5 (cinco) Estados americanos que não adotam os punitive damages (Louisiana, Nebraska, Washington, Massachusetts e Hampshire) ${ }^{5}$. Por conseguinte, o instituto dos punitive damages se apresentam de forma diversificada nos Estados norte-americanos que o utilizam, mesmo que substancialmente seja conceituado da mesma forma, como dispõe o $\S$ 908 do Restatement of Torts, elaborado pelo American Law Institute: “indenização que não a compensatória, concedida contra uma pessoa para puni-la por sua conduta ultrajante e dissuadi-la, e outras como ela, de praticarem condutas semelhantes no futuro"'.

Assim, os punitive damages se tornam um mecanismo importante para enfraquecer e impedir a perpetração de danos reiterados, com crassa desconsideração aos direitos alheios, assim como serve de instrumento para corrigir a insuficiência das funções reparatória/compensatória ${ }^{7}$ da responsabilidade civil no tocante à prevenção de danos, uma vez que é

4 Importante sublinhar que mesmo antes da formação da Federação, as 13 (treze) colônias inglesas nos Estados Unidos já gozavam de forte independência em relação ao poder central: "as comunas, em geral, só são submetidas ao Estado quando se trata de um interesse que chamarei de social, isto é, que elas partilham com outras." (TOCQUEVILLE, 2005, p. 76).

5 "four states (Louisiana, Nebraska, Washington, and Massachusetts) supreme courts have declared that their common law of tort does not permit these punitive damages. A fifth state (New Hampshire) abolished modern punitives by statute." (KRAUSS, 2007, p. 219-220).

6 Tradução livre da definição contida na dissertação de doutorado Integration of punitive damages into countries with a civil law system: mexico's case: "But, what are punitive damages? The Restatement of torts define them as: '1) damages, other than compensatory or nominal damages, award against a person to punish him for his outrageous conduct and deter him and others like him from similar conduct in the future." (VILLARREAL, 2009, p. 12).

7 A função mais tradicional da responsabilidade civil é a reparatória, consistente na fixação de um valor indenizatório capaz de reparar o dano da forma mais completa possível, na exata extensão do mesmo, em atenção ao princípio da restitutio in integrum, assegurando que a vítima seja recolocada no estado em que se encontrava antes do evento danoso, ou seja, em uma posição em que seus direitos estivessem inteiramente preservados, chamada de status quo ante. Dentro da função reparatória ainda existe a indenização por equivalente (geralmente em dinheiro) na hipótese de se tornar impossível ou muito difícil a indenização in natura com a reposição idêntica do bem, quando se abre a possibilidade de uma prestação equivalente. Por fim, diz-se que o dano moral é irreparável, tendo em vista que não pode ser objeto nem de reposição natural nem por equivalente, por impossibilidade absoluta de entregar coisa idêntica à vítima e/ou substituíla por equivalente. É nesse espectro que surge a função compensatória, no intento de fundamentar uma reparação do dano, ainda que irreparável, mantendo-se filiada à função reparatória, uma vez que não deve ultrapassar o suficiente para compensar o dano moral sofrido. 
limitada à exata extensão do dano ${ }^{8}$, medida esta que muitas vezes não promove resposta condizente com a gravidade da conduta do ofensor, especialmente quando os valores indenizatórios forem menores que os lucros obtidos com a conduta danosa.

Esta realidade de reiteração de danos e insuficiência do modelo de responsabilidade civil calcado apenas em uma visão reparatória/ compensatória se acentua ao se deparar com danos que pela sua pequena monta desestimulam a vítima em buscar a respectiva tutela juízo. Esses chamados pequenos danos beneficiam os ofensores, porque uma pequena parcela representativa das vítimas buscará a reparação, e, uma vez que o quantum debeatur seja proporcional à extensão do dano, os réus pagarão menos por terem investido menos em segurança e em qualidade do produto, serviço e/ou condições de trabalho, já que o preço para um padrão ótimo de suas atividades é inferior aos valores indenizatórios arbitrados judicialmente.

Sob a ótica apenas individual dos danos, há uma espécie de apatia racional (rational apathy) ${ }^{9}$ daqueles que optam por não ingressar no Judiciário, porque ao comparar os custos com o resultado esperado do julgamento, consideram que não vale a pena contratar advogado, pagar custas processuais, se deslocar para audiências ou sofrer risco de sucumbência. É claro que esse aspecto pode sofrer substancial influência de características próprias de cada país, pois no Brasil o âmbito dos juizados especiais e o correlato jus postulandi pode atenuar sutilmente esse desgaste, embora não sane o problema, tendo em vista que muitos danos produzidos em larga escala são de pequena proporção, sutis e

8 O CC/2002 estabelece, em seu artigo 944, que "a indenização mede-se pela extensão do dano".

9 Expressão cunhada por Louis T. Visscher (2009, p. 220) na obra "Economic analysis of punitive damages". 
quase insignificantes do ponto de vista individual, mas que considerados coletivamente representam conduta grave.

Contraditoriamente, os ofensores arcarão com menos por terem investido menos em suas atividades porque há danos que individualmente considerados são pífios e sob a ótica do custo-benefício envolvendo indenizações, despesas processuais e desgaste com a tramitação de um processo, tornam inviável o manejo de demanda. Como será visto no decorrer do presente artigo, a prática jurídica brasileira possui um viés individualista em se tratando dos punitive damages, ignorando que quando se está diante de danos em massa, a causa ganha dimensões coletivas e passam a ter relevância violações de direitos consideradas coletivamente, no campo das ações coletivas (MENDES, 2002, p. 31, 42).

Deste modo, Francis McGovern (2010, p. 452-453) acentua que "If a defendant is not obligated to pay for all the harm it causes, it will underinvest in safety" (se o réu não é obrigado a pagar por todo o mal que fez, ele vai investir menos em segurança), engendrando uma conclusão esdrúxula de que quem investe menos paga menos. Por consequência, quem arca com o prejuízo não suportado pelo ofensor é a sociedade ("society at large paid for them").

Por este motivo existe um sólido fundamento econômico por trás da aplicação dos punitive damages, que lhe dá sustentáculo e legitimidade como instrumento de prevenção de danos e vai muito além de uma perspectiva unicamente punitiva. Isto porque os punitive damages possibilitam o desestímulo (deterrence) de condutas (VISSCHER, 2009, p. 219) pelo simples fato de promover a readequação de comportamentos a partir da internalização de altos custos por conta de indenizações fixadas para além do suficiente para compensar ou reparar os prejuízos, tornando a conduta danosa desvantajosa do ponto de vista 
econômico: "esta lógica pode trazer como consequência a noção de que quanto mais cuidado menos danos, menos custos"10 (VISSCHER, 2009, p. 220, tradução nossa).

Este raciocínio econômico exige que o valor indenizatório seja alto o suficiente para que o ofensor internalize os danos que causou, o fazendo tomar o devido cuidado em sua atividade, trazendo como lição que é vantajoso manter um nível ótimo de qualidade e atendimento e arcar com menos indenizações (carregadas pelos punitive damages) ao invés de conservar um nível baixo de qualidade e ser obrigado a pagar altas indenizações (VISSCHER, 2009, p. 220).

Apesar da importante função a ser desempenhada pelos punitive damages quanto à punição e desestímulo de condutas indesejadas e graves e da inequívoca aplicação do instituto por tribunais e juízes em demandas judiciais no Brasil, surge a problemática a ser enfrentada pelo presente artigo: quais os requisitos subjetivos e objetivos que autorizam à incidência dos punitive damages? Esses requisitos existem e são reconhecidos na experiência de aplicação do instituto no Direito brasileiro? Em caso negativo, de que modo o a experiência brasileira pode aprimorar a aplicação dos punitives damages de modo a torna-la mais técnica, coerente, legítima e com arrimo teórico?

Essas questões são relevantes ante a possibilidade de a partir de um uso teoricamente adequado dos punitive damages se potencializar o propósito de coibir condutas gravosas e de promover a utilidade do instituto no plano pedagógico, tendo como ponto de partida o aperfeiçoamento dos punitive damages. Acentua-se a importância

10 "The threat of being held liable induces the actors to incorporate the possible losses of others into their decision on how much care to take and how often to engage in the activity. Taking more care and/or reducing the activity level can lower the probability of an accident and thereby the expected accident losses." 
do trabalho, visto que ao apresentar critérios para aferir o cabimento dos punitive damages, pode servir como farol e guia aos intérpretes do direito.

Para tanto, a pesquisa partirá do pressuposto de que os punitive damages tem cabimento no ordenamento jurídico brasileiro, assim como mergulhará nos pressupostos desenvolvidos pela teoria e jurisprudência da prática dos punitive damages nos Estados Unidos, onde o instituto ganhou lapidação exponencial nas últimas décadas em especial por meio das decisões da Suprema Corte Americana, pelo que o estudo comparado pode permitir um diálogo profícuo com o direito brasileiro e possibilitar o suprimento de insuficiências teóricas do caso brasileiro.

\section{DESENVOLVIMENTO DOS PUNITIVE DAMAGES NA EXPERIÊNCIA JURÍDICA DOS EUA: REQUISITOS OBJETIVOS E SUBJETIVOS}

\subsection{Bases do desenvolvimento dos punitives damages: o papel do júri e a regra do stare decisis}

Antes de adentrar nos requisitos subjetivos e objetivos dos punitive damages, inarredável esclarecer dois aspectos fundamentais do caso americano que constituem pilares para o entendimento dos pressupostos dos punitive damages: a participação do júri e a regra do stare decisis.

Um traço marcante dos punitive damages nos Estados Unidos é que o procedimento para a fixação dos punitive damages tem a 
inarredável participação do júri, formado por cidadãos leigos de um determinado território que representam a sociedade. No Brasil, o júri julga apenas crimes dolosos contra a vida (artigo $5^{\circ}$, XXXVIII, da $\mathrm{CF} / 1988)$.

Convém esclarecer que apesar da exclusividade do júri para julgar e estabelecer o montante dos punitive damages, todos os contornos desta decisão ficam sujeitos a posterior revisão judicial a partir de recursos: "o regime dos nossos punitive damages, em contraste, permanece permitindo ilimitada discricionariedade ao júri, estando sujeito ao reexame judicial apenas posteriormente." ${ }^{11}$ (PRIEST, 2003, p. 4).

Como o júri é composto de cidadãos leigos do ponto de vista do Direito, existe preocupação com a sua instrução pelo fato de a tomada de decisão lhe competir, de modo que a procedência ou não dos punitive damages é de sua total responsabilidade (PRIEST, 2003, p. 7-8). Primeiro, o júri deve apreciar se o réu é responsável pelos danos causados à vítima, para em seguida em caso de resposta positiva definir em que monta deve ser fixada a indenização compensatória em estrita harmonia com o efetivo dano sofrido. Portanto, "o júri enfrentará os punitive damages somente se o réu houver sido responsabilizado e os danos compensatórios fixados." 12 (PRIEST, 2003, p. 8-9, tradução nossa).

A avaliação dos punitive damages pelo júri é delicadamente conduzida por perguntas específicas, justamente para suprir a falta de conhecimento jurídico dos seus componentes. Assim, a incidência

11 "our punitive damages regime, in contrast, remains committed to allowing the jury unlimited discretion to award any amount, subject only to subsequent judicial review."

12 "The jury will reach the punitive damages issue only if it both finds defendant liable and awards the plaintiff some level of compensatory damages." 
ou não dos punitive damages é esclarecida em conformidade com as respostas do júri sobre os principais elementos objetivos e subjetivos que caracterizam uma conduta altamente reprovável. Por exemplo, o júri deve responder um questionário sobre se considera que a conduta do réu foi intencional, maliciosa, imprudente e/ou com total indiferença aos direitos de outrem, para o fim de averiguar se o réu, mesmo ciente das circunstâncias que importassem em danos para outras pessoas, prosseguiu com a atitude indiferente, omissiva ou comissivamente.

Em que pese a grande variedade de perguntas que possam ser feitas ao júri para identificar a incidência dos punitive damages, há uma espécie de tronco comum entre todas as exigências: “Apesar de haver algumas diferenças entre os estados, os termos mais usados como bases para os punitive damages são 'imprudência', 'descaso', 'maldade', 'opressão', 'censurabilidade', 'comportamento ultrajante'”13 (PRIEST, 2003, p. 13, tradução nossa).

Quanto a regra do stare decisis no direito norte-americano, vale destacar que ela traz a ideia central segundo a qual juízes e tribunais são obrigados a seguir as decisões anteriores e não tumultuar o que já foi solucionado pelo Poder Judiciário, "exigindo do magistrado a mesma decisão para o mesmo problema a partir da vinculação à decisão mais antiga, ou seja, a que precedeu, o precedente"14 (DAINOW, 1996, p. 424, tradução nossa). Contudo, a utilização de precedentes na experiência da tradição common law não se revela como algo simplório e menos complexo do que a interpretação de leis, pois há cuidado exacerbado com os fatos da causa que formou o precedente, já que a vinculação da

13 "Although there are some differences across states, the terms most commonly used as bases for a punitive damages award are 'recklessness', 'reckless disregard', 'maliciousness', 'oppression', reprehensibility', 'egregious or outrageous behavior"'.

14 “ $[\ldots]$ the same result had to be reached for the same problem [...] obliged to 'follow' the earlier decision, the precedent".

SCIENTIA IURIS, Londrina, v.22, n.1, p.190-222, mar.2018 DOI: 110.5433/2178-8189.2018v22n1p190 
decisão se refere apenas às razões de decidir (ratio decidendi). Nesse sentido:

Portanto, o sistema da common law, com a sua forma de análise caso a caso, $[\ldots]$ colocou um foco forte sobre os fatos e raciocínio em relação a esses fatos, assim como ao direito de cada precedente, uma vez que o estilo do julgamentos lida com a articulação detalhada dos casos que aparecem semelhante"15 (BANKOWSKI et al., 1997, p. 489 , tradução nossa).

Essas razões de decidir são construídas com base nos fatos que envolvem a demanda, tornando vinculativo o entendimento jurídico esposado para outros casos com fatos similares (BANKOWSKI et al., 1997, p. 488-489). Ou seja, o foco na aplicação do precedente são os fatos considerados em toda a sua complexidade, o que implica no constante exercício de distinguir (distinguish) um caso atual com o anterior, podendo o juiz deixar de aplicar o precedente por não haver similaridade de fatos, assim como pode o juiz rever o entendimento manifestado na decisão precedente, por causa de transformações históricas, jurídicas ou de interpretação constitucional, estabelecendo nessa hipótese um novo precedente em um fenômeno denominado de “overruling”(DAINOW, 1996, p. 426).

A regra do stare decisis, baseada no respeito às decisões anteriores, se manifesta mais fortemente nos países de tradição common law, e possui como justificativa a necessidade de garantir segurança jurídica, estabilidade e previsibilidade por parte dos cidadãos de como se dará a aplicação das normas jurídicas (BANKOWSKI et al.,

15 "Thus, common law systems with their case-by-case way of arguing [...] put a particularly strong focus on the facts and the reasoning about facts and law in each precedent, since the style of the judgments deals with the detailed articulation of cases that appear similar". 
1997, p. 488), assim como também o valor de tratamento igualitário dos jurisdicionados pelo Poder Judiciário a partir da uniformidade de decisões ${ }^{16}$, fortalecendo a técnica do precedente como um elemento central.

Outros valores sustentam o respeito às decisões anteriores na common law, tais como a economia de esforço pelo Poder Judiciário, que não precisará construir novamente uma decisão para um conjunto de fatos; o aumento da confiança nas relações privadas pela solidez dos desdobramentos jurídicos constantes em precedentes, além da atenuação da litigação aventureira, pois já se sabe com alto grau de confiabilidade o desfecho de determinada lide (BANKOWSKI et al., 1997, p. 490).

Em outros termos, é fundamental para a tradição jurídica da common law que a interpretação da lei seja uniforme e comum em todo o Estado, "garantindo a integridade do Estado como apoiador de um sistema legal único" (BANKOWSKI et al., 1997, p. 487, tradução nossa) de modo a fomentar a coerência de todo o ordenamento jurídico e a sua correlata aplicação, utilizando como instrumento a força vinculativa dos precedentes, tornando-os obrigatórios em casos semelhantes ou iguais (BANKOWSKI et al., 1997, p. 487).

No caso dos punitive damages, a Suprema Corte Americana tem construído os contornos dos punitive damages no tocante as características da conduta praticada, assim como quanto aos parâmetros para fixação do quantum indenizatório, já que se entende que "quando a indenização fixada for considerada abusiva, haverá violação da Due

16 Nesse sentido: "uniformity of law is an essential art of equality of treatment of essentially similar cases, that is, cases which qualify as similar under a given (and stable) interpretation of the law" (BANKOWSKI et al., 1997, p. 488, tradução nossa): "Assim, a uniformidade do direito é uma arte essencial de igualdade de tratamento dos casos essencialmente similares, ou seja, casos que se qualificam como semelhante ao abrigo de uma interpretação (estável) da lei”. 
Process Clause of the Fourteenth Amendment, obtendo-se, então, o permissivo para o recurso à Suprema Corte Americana" (MORAES, 2009 , p. 232-233). Acrescenta-se que o histórico de todos os nove casos já julgados pela Suprema Corte sobre punitive damages tinham alegações de violações também da $5^{\mathrm{a}}$ e da $8^{\mathrm{a}}$ Emenda Constitucional ${ }^{17}$ : a primeira é considerada uma complementação da $14^{\mathrm{a}}$ na formação do princípio do devido processo legal e a $8^{\mathrm{a}}$ estabelece a proibição de condenações em penas excessivas ${ }^{18}$.

As referidas Emendas têm forte conteúdo principiológico e são de grande complexidade se interpretadas a fundo e em consonância com os precedentes dos tribunais, contudo, são pertinentes aos punitive damages na medida em que determinam que ninguém será privado de seus bens sem o devido processo legal (Emenda V e XIX), nem tampouco será compelido a pagar multas excessivas (Emenda VIII). Desta forma, o argumento jurídico para demonstrar o não cabimento dos punitive damages - além da utilização de provas que apontem para a inexistência de elementos objetivos e subjetivos e/ou de alegação pautada em precedentes anteriores - se baseia na afirmação de que o

17 Em estudo direcionado aos julgamentos realizados pela Suprema Corte norte-americana que envolveram punitive damages, Vanessa Burrows (2007, p. 2), após analisar caso a caso constata que "a indenização punitiva tem sido acusada de violar a oitava emenda relacionada a proibição de penas excessivas, assim como de violar a quinta e décima quarta Emendas Constitucionais, que juntas constituem a cláusula do devido processo legal.” (Tradução nossa).

18 "EMENDA V - Ninguém será detido para responder por crime capital, ou outro crime infamante, salvo por denúncia ou acusação perante um Grande Júri, exceto em se tratando de casos que, em tempo de guerra ou de perigo público, ocorram nas forças de terra ou mar, ou na milícia, durante serviço ativo; ninguém poderá pelo mesmo crime ser duas vezes ameaçado em sua vida ou saúde; nem ser obrigado em qualquer processo criminal a servir de testemunha contra si mesmo; nem ser privado da vida, liberdade, ou bens, sem processo legal; nem a propriedade privada poderá ser expropriada para uso público, sem justa indenização. [...] EMENDA VIII - Não poderão ser exigidas fianças exageradas, nem impostas multas excessivas ou penas cruéis ou incomuns. [...] EMENDA XIV Seção 1. Todas as pessoas nascidas ou naturalizadas nos Estados Unidos, e sujeitas a sua jurisdição, são cidadãos dos Estados Unidos e do Estado onde tiverem residência. Nenhum Estado poderá fazer ou executar leis restringindo os privilégios ou as imunidades dos cidadãos dos Estados Unidos; nem poderá privar qualquer pessoa de sua vida, liberdade, ou bens sem processo legal, ou negar a qualquer pessoa sob sua jurisdição a igual proteção das leis." (UNITED STATES SENATE, 2014, tradução nossa). 
valor da indenização que ultrapassa o suficiente para compensar o dano representa apropriação indevida (ilegal) de bens do réu pelo Estado ou pela vítima, sem observância do devido processo legal que sustente o referido montante, e, na defesa de que o valor fixado foi excessivo, o que por si só violaria o direito constitucional de não imposição de multas descomunais.

Portanto, a evolução dos punitive damages é marcada muito mais pelo desenvolvimento de decisões judiciais do que pela produção de textos legais, de modo que para que os punitive damages sejam aplicados na experiência norte-americana, o julgador (leia-se júri e por consequência o juiz que avaliará o entendimento do júri) deve respeitar algumas condições e estar atento para a presença de alguns elementos de ordem objetiva e subjetiva.

A base destes requisitos está no questionário que é entregue ao júri e fundamenta o seu julgamento, o qual possui certa uniformidade de conteúdo em diversos Estados que permitem a aplicação dos punitive damages. A lapidação desses pressupostos também é encontrada nos precedentes da Suprema Corte do país, que teve o importante papel de estabelecer parâmetros para a investigação do grau de censurabilidade da conduta do réu.

\subsection{Requisitos objetivos e subjetivos dos punitive damages a partir do papel do júri e da doutrina}

Quanto aos elementos objetivos, ou seja, aqueles que independem de qualquer vontade do réu, constata-se 1) o dano (that plaintiff has suffered some harm); 2) o nexo de causalidade (that the defendant caused the harm to the plaintiff) e 3) o ato ilícito extracontratual 
(that, in causing the harm, the defendant violated some legal standard controlling conduct in the society) (PRIEST, 2003, p. 8-9), cabendo salientar que a incidência dos punitive damages em se tratando de atos ilícitos contratuais (breachs of contract) ainda é tema controvertido, uma vez que "a maior parte das jurisdições americanas não permite punitive damages por quebra de contrato, a menos que o descumprimento venha acompanhado também de um ilícito extracontratual."19 (DODGE, 1999, p. 629, tradução nossa). Estes requisitos em geral se relacionam com os pilares da própria responsabilidade civil, de modo que os punitive damages só se tornam viáveis se antes o réu for declarado responsável pelos danos suportados pela vítima e seja atribuído a ele um montante a ser pago a título de compensatory damages (indenização compensatória/ reparatória) (PRIEST, 2003, p. 9).

Cabe um parêntese quando ao requisito do dano, em que pese já ter sido explicitado em momento anterior do trabalho, na experiência norte-americana deve ser ressaltado que os "punitive damages" e os "nominal damages" se inserem no rol dos "non-compensatory damages", pois ambos possuem o viés de atribuir obrigação de indenizar ao ofensor sem que esse valor indenizatório seja fixado apenas para reparar ou compensar o prejuízo, por isso são consideradas verbas "não compensatórias"(MENYHARD, 2009, p. 88).

Desta feita, o "nominal damages" foi desenvolvido enquanto categoria jurídica para simbolizar uma condenação em face de uma conduta censurada pelo ordenamento jurídico que por alguma razão não causou danos a ninguém. Por meio desse instrumento é possível o magistrado fixar valor indenizatório a título de "nominal damages"

19 "the majority of American jurisdictions do not allow punitive damages for breach of contract unless the breach constitutes an independent tort".

SCIENTIA IURIS, Londrina, v.22, n.1, p.190-222, mar.2018 DOI: 110.5433/2178-8189.2018v22n1p190 
com o objetivo de realçar que no caso houve lesão a um interesse juridicamente protegido.

Ao contrário do que possa parecer, o "nominal damages" fortalece o raciocínio de que um dos elementos dos punitive damages é a existência de dano, pois mesmo em casos onde não houve danos, o magistrado ainda sim precisa se valer desse mecanismo para fixar ao menos uma condenação simbólica, pois do contrário os punitive damages não seriam viabilizados: "praticamente todos os estados que permitem os punitive damages exigem que o dano seja demonstrado, nem que seja apenas um nominal damages"20 (SEBOK, 2007, p. 171, tradução nossa).

Retomando o itinerário do julgamento realizado pelo júri, vêm então as questões relacionadas aos requisitos subjetivos, que apontam para perguntas sobre se o júri considera que o réu foi demasiadamente imprudente de modo a serem necessários os punitive damages para detêlo de agir dessa maneira novamente, se agiu com extremo descaso e alto grau de desrespeito aos direitos, se seu comportamento foi arquitetado maliciosamente, dentre outras. ${ }^{21}$

Os requisitos subjetivos, ao contrário dos objetivos, não são cumulativos, e exigem, para que a conduta seja passível de punitive damages, a presença de apenas uma das hipóteses de cunho subjetivo descritas e explicadas adiante: malicious, reckless disregard e gross negligence. ${ }^{22}$

A má-intenção (malicious), a imprudência (reckless) e a

20 "[...] virtually every state that permits punitive damages has maintained, however, that actual damage, even if only nominal, must be shown to merit an award of punitive damages."

21 Como exemplo de pergunta ao júri: "Did the defendant behave with reckless disregard? [...] Do you think the defendant's actions were a reckless level to justify punitive damages?" (PRIEST, 2003, p. 11, tradução nossa): "O réu agiu com imprudência grave? [...] Você acha que o nível da imprudência do réu justifica a aplicação dos punitive damages?"

22 Classificação adotada com base nos estudos de Alexander Volokh (1996) e Hastie, Schkade e Payne (2002). 
negligência (negligent) constituem o tripé dos requisitos subjetivos. $\mathrm{O}$ ato malicioso, como requisito subjetivo, por si só basta para a incidência dos punitive damages enquanto que a imprudência e a negligência devem ser graves e desmedidas pela indiferença e descaso a tal ponto que a censurabilidade do comportamento seja mais alta do que um simples descuido(HASTIE; SCHKADE; PAYNE, 2002, p. 88).

A expressão "reckless disregard", comumente utilizada para marcar os punitive damages, indica a imprudência (reckless) qualificada pela indiferença (disregard) com os direitos alheios, tornando a conduta mais censurável do que outras imprudentes, pelo simples fato de o réu ter agido com ou se mantido em um estado de indiferença, ignorando os riscos de perpetração de danos, mesmo conhecendo-os. Assim, a imprudência é "o conhecimento e desconsideração consciente de um risco injustificável de dano"23 (VOLOKH, 1996, p. 3, tradução nossa).

Um exemplo de imprudência com total indiferença diz respeito a um empregador, que, após realizar testes de segurança, sabia que o uso de determinado equipamento não garantiria a proteção adequada ao trabalhador, mas pensando em poupar gastos, decidiu adotar mesmo assim este equipamento em detrimento de outro mais caro. $\mathrm{O}$ empregador sabia dos riscos e nada fez para incrementar a segurança do trabalhador.

A gross negligence (negligência grave), de outro lado, se manifesta quando "o réu deveria ter conhecimento do risco de que danos injustificáveis poderiam ocorrer com o seu ato, mas não teve"24 (VOLOKH, 1996, p. 3, tradução nossa). Neste caso, o réu deveria ter conhecimento das circunstâncias que tornariam a sua conduta danosa,

23 "Recklessness is the knowledge and conscious disregard of a substantial and unjustifiable risk of harm." 24 "Negligence is when the defendant should have known, but didn't, of a substantial and unjustifiable risk that the damage would occur." 
porém, em um nível inaceitável e grave não pautou seu ato em questões que deveria ter conhecimento para evitar o dano.

Um exemplo de negligência grave é o caso de companhia especializada em estudo de qualidade de água, que, após ser contratada para atestar se a qualidade da água de determinada comunidade estava dentro dos níveis de qualidade exigidos, não atestou a quantidade de componente químico danoso à saúde por ter passado despercebido no estudo. Pela natureza da atividade, a companhia deveria atestar a incidência do composto químico, mas por negligência grave não o fez.

Por este motivo, a doutrina tem buscado descrever o conjunto de ações que devem ser praticadas para que a imprudência e a negligência atinjam o patamar propício para a incidência dos punitive damages. Como dito, há uma tentativa de descrever uma ordem sucessiva de atos que possam caracterizar a imprudência ou a negligência como atos graves e censuráveis via punitive damages, conforme resumido abaixo.

Primeiramente, deve o réu ter a consciência do perigo (conscious of danger), estando subjetivamente ciente do risco e da previsibilidade de ocorrência de danos por meio de sua conduta. Em segundo lugar, deve o réu se portar com indiferença perante este risco (disregard danger), o que indica que mesmo após saber dos riscos de sua atividade ou de seu ato isoladamente, a apatia subsistiu. Em terceiro plano, o comportamento do réu deve ser marcado por um grave desvio (gross deviation), de modo que no momento de decidir como agir, o réu tenha optado pelo caminho do perigo e da produção de danos. Em último lugar e complementando as fases anteriores, deve a conduta do réu ser caracterizada por um desvio patente de cuidado (dangerous outcome) de tal modo que uma pessoa comum não incorreria (HASTIE; SCHKADE; PAYNE, 2002, p. 88). 
Percebe-se, em suma, que o ato ou a sucessão de atos devem ser marcados pela culpa, pois tanto na conduta má-intencionada como na imprudente ou negligente a doutrina supracitada exige ou que o réu tenha causado danos conscientemente ou que não tenha considerado o risco de que os danos pudessem ocorrer ou que não tinha conhecimento do risco de ocorrência dos mesmos, embora devesse saber. Contudo, no tocante a este último aspecto subjetivo (negligência), é possível iniciar digressão que conduza a questão para uma esfera que prescinda da culpa.

Enquanto que os atos mal-intencionados e imprudentes envolvem a consciência de prejudicar alguém, o ato negligente pode ser tão grave a ponto de os seus próprios resultados apontarem para a desnecessidade de quaisquer elementos subjetivos, pelo simples fato de ficar escancarada a baixa ou nenhuma preocupação com investimento em segurança e/ou qualidade de sua atividade.

Por via de consequência, se o réu tivesse investido o suficiente em segurança e qualidade, os danos não teriam ocorrido, quando se conclui que se os danos se manifestaram em um nível inaceitável, das duas uma: ou o réu não tem controle sobre sua atividade ou logicamente não tem tido o cuidado devido, sendo inócuo investigar aspectos relacionados à subjetividade (vontade) do ofensor. Nesse sentido, Alexander Volokh (1996, p. 19) relaciona a relação entre maior investimento e prevenção de danos:

Acidentes sempre acontecem, mesmo sob uma gestão responsável. Esta não é uma hipérbole; a menos que se evite completamente um determinado setor, mas eliminar todas as chances de um acidente é literalmente impossível. Podemos reduzir os acidentes; por gastar mais recursos na prevenção, podemos evitar mais 
acidentes, mas esses esforços custam dinheiro, e quanto maior o nível de segurança, maior o custo para evitar que cada acidente. Se fôssemos tentar eliminar todos os acidentes, acabaríamos subindo a extremos, gastando incontáveis recursos que seriam mais bem investidos em outros setores (Tradução nossa) ${ }^{25}$.

Destarte, como prevenir danos custa muito caro em um contexto de consumo e trabalho em sintonia para o excesso, dever-se-á abraçar a teoria do risco calcada na responsabilidade objetiva para os punitive damages em alguns casos, pois, se o consumo e o trabalho estão em ritmo desenfreado e, por outro lado, prevenir o dano a vidas e direitos custa muito caro, nada mais adequado do que estabelecer não apenas a indenização sem a necessidade de demonstrar a culpa para as vítimas de danos ocasionados por atividades eminentemente danosas, como também a possibilidade de incidência dos punitive damages para fazer frente ao descontrole de uma atividade, ultrapassando a afirmação de que "se a falha não é intencional, então é desnecessária para fins de dissuasão e punição a imposição do punitive damages em conjunto com a indenização compensatória"26 (COOTER, 1982, p. 79, tradução nossa).

Não se está aqui a dizer que a culpa deve ser relegada a um segundo plano ou que a má-intenção, a imprudência e a negligência não são mais necessárias para a caracterização de uma conduta grave. Pelo contrário, a pesquisa apenas aponta para um novo horizonte que se abre na interface dos punitive damages (que tradicionalmente têm sido

\footnotetext{
25 "Accidents will always happen, even under the most responsible management. This isn't hyperbole; unless one completely avoids a particular industry, eliminating all chance of an accident is literally impossible. We can reduce accidents, though; by spending more resources in prevention, we can prevent more accidents, but these efforts cost money, and the higher the level of safety, the more it costs to prevent each additional accident. If we were to try to eliminate all accidents, we would end up going to extreme lengths, spending countless resources that would be better spent elsewhere".

26 "If fault is unintentional, then imposing punitive damages in addition to compensatory damages is both unnecessary for deterrence and undeserved as punishment."
} 
alicerçados sobre as bases da culpa) com outra categoria jurídica que simplesmente prescinde de qualquer culpabilidade.

Desta forma, o extremo descaso e alto grau de desrespeito aos direitos - enquadrados como requisitos subjetivos - podem ser caracterizados apenas pela demonstração do dano, principalmente em sede de uma ação coletiva, onde o grau de censurabilidade da conduta do réu é exposto de forma mais fidedigna do que em uma ação individual pelo retrato cristalino do exército de vítimas.

Nesse sentido, o estudo dos requisitos subjetivos dos punitive damages conjugado com danos que são praticados em larga escala permite alcançar um cenário onde é possível a erosão e rompimento da culpa como requisito basilar para a incidência dos punitive damages e da consequente responsabilização do réu, já que "verifica-se uma crescente conscientização de que a responsabilidade objetiva consiste em uma responsabilização não pela causa [...], mas pelo resultado (dano)" (SCHREIBER, 2006, p. 30).

De outro lado, oferecendo um argumento subsidiário a uma interpretação mais rigorosa acerca da exigência da culpa para a aplicação dos punitive damages, pode ser dada uma dose de objetividade no próprio elemento culpa, a partir do divórcio de seu caráter psicológico. Nesse sentido:

[...] Preocupações com a consciência da lesão ao direito alheio, com a previsibilidade do dano e com a reprovabilidade moral da conduta praticada esmoreceram diante das dificuldades de concreta demonstração destes aspectos, culminando com a consagração da chamada culpa objetiva. Sob tal designação, a culpa passou a ser entendida como 'o erro de conduta', apreciado não em concreto, com base nas condições e na capacidade 
do próprio agente que se pretendia responsável, mas em abstrato, isto é, em uma objetiva comparação com um modelo geral de comportamento. [...] Se de tal comparação resultar que o dano derivou de uma imprudência, imperícia ou negligência do autor do dano, nos quais não incorreria o homem padrão, criado in abstracto pelo julgador, caracteriza-se a culpa, ou seja, o erro de conduta. [...] implica um flagrante divórcio entre a culpa e sua tradição moral. $\mathrm{O}$ agente não é mais tido em culpa por ter agido de forma reprovável no sentido moral, mas simplesmente por ter deixado de empregar a diligência social média (SCHREIBER, 2006, p. 34-37).

Desta forma, mesmo que se admita a indispensabilidade da culpa para a incidência dos punitive damages, quando o julgamento do comportamento do agente é realizado de forma abstrata, alheio à intenção e demais aspectos subjetivos do agente, a culpa se torna objetivada, tornando possível a sua caracterização mesmo em face de um agente que agiu com todo o cuidado possível e ainda assim não obteve êxito no controle de produção de danos de seu ato ou conjunto de atos.

\subsection{Requisitos objetivos e subjetivos dos punitive damages a partir da interpretação dos limites constitucionais e pressupostos dos punitive damages pela suprema corte americana}

Ao lado dos pressupostos objetivos e subjetivos acima alinhavados, outros critérios importantes para a aplicação dos punitive damages e aferição do grau de censurabilidade da conduta (the degree of reprehensibility of the defendant's misconduct) vêm sendo paulatinamente acrescentados pela Suprema Corte Americana na análise de recursos contra a fixação da indenização pelo Tribunal do Júri.

Como a conduta reprimida pelos punitive damages deve 
ser insultuosa e grave, em se tratando de um país com tradição de observância do "stare decisis", nada mais natural que a evolução do tema seja resultado das decisões da Suprema Corte Constitucional, embora seja inequívoco que os precedentes daí advindos são profundamente influenciados pelas decisões das outras cortes de justiça do país e das fundamentações construídas pelos advogados.

Nas últimas décadas a Suprema Corte Americana julgou nove casos envolvendo punitive damages: Browning-Ferris Indus., Inc. v. Kelco Disposal (1989); Pacific Mutual Life Ins. Co. v. Haslip (1991); TXO Production Corp. v. Alliance Resources Corp. (1993); Honda Motor Co. v. Oberg (1994); BMW of North America, Inc. v. Gore (1996); Cooper Industries, Inc. v. Leatherman Tool Group (2001); State Farm Insurance v. Campbell (2003); Philip Morris v. Williams (2007) e Exxon Shipping Co v. Baker (2008) $)^{27}$.

Destarte, o presente artigo se deterá na análise dos casos $B M W$ of North America, Inc. v. Ira Gore (1996) e State Farm Insurance v. Campbell (2003), os quais representaram um verdadeiro marco na interpretação dos punitive damages e formação de pressupostos para a sua incidência e fixação. No primeiro deles, além de ter decidido que uma indenização 500 vezes maior do que a compensatória violava a cláusula do devido processo legal, desenvolveu três parâmetros para que o magistrado pudesse decidir por um valor punitivo dentro dos limites constitucionais: "(1) o grau de censurabilidade da conduta do réu, (2) a proporção razoável entre a punição e os danos causados, e (3) as sanções civis e criminais autorizadas impostas em casos semelhantes"28

27 Vanessa Burrows (2007, p. 2) acentua que nas últimas décadas a Suprema Corte Americana julgou oito casos que envolveram punitive damages. Contudo, no ano de 2008, em momento posterior ao estudo em comento, a Corte decidiu o caso Exxon Shipping Co. v. Baker, pelo que se considera que foram nove casos julgados até o momento.

28 "(1) the degree of reprehensibility of the defendant's conduct, (2) a reasonable ratio of punitive to 
(BURROWS, 2007, p. 3, tradução nossa).

Duas grandes contribuições foram sedimentadas pela Suprema Corte em 2003, ao julgar o caso State Farm vs Campbell. Primeiramente, a Corte estabeleceu que a proporção entre os danos compensatórios e os punitivos não pode ser superior do que uma razão de 9 pra 1, ressaltando que apenas em raríssimas exceções uma proporção maior do que esta satisfaz a cláusula do devido processo legal(BURROWS, 2007, p. 3-4).

Posteriormente, decidiu que o grau de censurabilidade da conduta do réu já mencionado na decisão $B M W$ vs Gore deverá ser avaliado levando-se em conta os seguintes aspectos: (1) se houve dano físico ou somente econômico; (2) se o ato ilícito evidenciou indiferença ou demasiado desrespeito à saúde ou segurança dos outros; 3) se a vítima era pessoa financeiramente vulnerável; (4 ) se a conduta foi reiterada ou um incidente isolado; 5) se o dano foi o resultado de um conduta intenção, negligência ou imprudência.

Cabe uma reflexão acerca desses aspectos, pois se defende que não é apenas a vulnerabilidade financeira que deveria estar em pauta, pois há outras vulnerabilidades, como a técnica e a jurídica que poderiam constar no rol acima. Quanto ao item 5) acentua-se que os elementos subjetivos podem ser relativizados casos onde os danos externem por si só a gravidade da conduta. Por fim, considera-se adequada a inclusão do interesse de conservação da empresa como elemento norteador para a fixação dos punitive damages, uma vez que as mesmas geram empregos, arrecadam impostos e também geram bem-estar social com serviços e produtos.

Em suma, estes degraus de análise são acrescentados e devem

compensatory damages, and (3) comparable civil and criminal sanctions, i.e. the difference between this remedy and the civil penalties authorized or imposed in comparable cases." 
ser interpretados em conjunto com o rol de requisitos subjetivos e objetivos descritos pela doutrina, uma vez que são fundamentais para o esclarecimento se o comportamento em julgamento deve ser censurado a ponto de o seu desestímulo ser objeto de condenação em punitive damages.

De fato, uma conduta que foi reiterada, atingiu pessoa vulnerável, foi praticada com indiferença e causou dano físico é altamente grave, e, por este motivo, o Tribunal realçou que apenas um desses fatores pode não ser suficiente para ensejar a indenização punitiva, mas que a inexistência de todos eles torna os punitive damages praticamente inviáveis ${ }^{29}$.

Resumidamente, sob a ótica dos parâmetros desenvolvidos pela jurisprudência da Suprema Corte Americana no caso BMW of North America, Inc. v. Ira Gore (1996) e Farm State vs Campbell (2003), é possível estabelecer que esses precedentes, juntos, sedimentaram o seguinte raciocínio: para julgar a possibilidade jurídica de aplicação dos punitive damages e o consequente valor indenizatório deve o magistrado analisar (1) o grau de censurabilidade da conduta do réu e (2) a proporção razoável entre a punição e os danos causados. Ao avaliar o grau de censurabilidade do réu, inarredável indagar a) se houve dano físico ou somente econômico; b) se o ato ilícito evidenciou indiferença ou demasiado desrespeito à saúde ou segurança dos outros; c) se a vítima era pessoa financeiramente vulnerável; d) se a conduta foi reiterada ou um incidente isolado; e) se o dano foi o resultado de uma conduta com

29 "The Court began its analysis under the first guidepost - the degree of reprehensibility of the defendants misconduct. Under this guidepost, courts should consider whether: (1) the harm caused was physical as opposed to economic; (2) the tortious conduct evinced an indifference to or a reckless disregard for the health or safety of others; (3) the target of the conduct was financially vulnerable; (4) the conduct involved repeated actions or was na isolated incident; and (5) the harm was the result of intentional malice, trickery, deceit, or mere accident" (JAYNE, 2002, p. 885). 
intenção, negligência ou imprudência.

Estes critérios para aferir quão grave foi o comportamento do réu se somam aos requisitos objetivos e subjetivos anteriormente mencionados engendrando uma moldura sobre a qual o magistrado e o júri devem se ater no momento de apreciar questões relacionadas aos punitive damages. Essa moldura é relevante para a pesquisa na medida se visa a conhecer os requisitos objetivos e subjetivos dos punitive damages assim como averiguar se esses pressupostos são reconhecidos na experiência de aplicação do instituto no Direito brasileiro.

\subsection{Resumo dos requisitos objetivos e subjetivos dos punitive damages: parâmetros orientadores}

Considerando que a incidência dos punitive damages necessita da constatação de uma conduta de alto grau de censurabilidade e reprovação, visando a somar as contribuições teóricas da doutrina, das práticas do júri e da Suprema Corte Americana, segue abaixo lista com parâmetros úteis para o intérprete do direito aferir o cabimento ou não dos punitive damages:

- razoabilidade entre o valor da indenização punitiva e dano causado, visando a promover desestímulo da conduta;

- se o dano causado foi físico ou somente econômico. Nessa hipótese, o dano apenas material torna mais remota a aplicação dos punitive damages e o dano físico aproxima a sua incidência. Acrescenta-se que sob a ótica do presente trabalho, deve ser avaliada a existência de danos existências, mesmo que não tenham relação com danos físicos; 
- se a conduta evidenciou indiferença ou demasiado desrespeito à saúde ou segurança dos outros;

- se a vítima era financeiramene vulnerável. Alerta-se que há outros tipos de vulnerabilidade, como a técnica, informacional, fática e sociocultural, de modo que se aconselha a análise completa da existência de vulnerabilidade;

- se a conduta foi reiterada ou um incidente isolado;

- se o dano foi o resultado de uma conduta com intenção, negligência ou imprudência. Neste ponto uma digressão, visto que há danos causados em larga escala, os quais representam por si só a negligência ou imprudência, tornando desnecessária prova nesse sentido;

- se o ofensor tinha a consciência do perigo, estando subjetivamente ciente do risco e da previsibilidade de ocorrência de danos por meio de sua conduta;

- se o ofensor se portou com indiferença perante este, e, mesmo após saber dos mesmos, não tomou providências preventivas;

- se comportamento do réu foi marcado por uma escolha do ponto de vista econômico em detrimento da segurança e qualidade;

- se o ofensor tivesse investido o suficiente em segurança e qualidade, os danos não ocorreriam.

Conclui-se que esses parâmetros, embora possam servir de guia para o intérprete no caso brasileiro, não exaurem a possibilidade de surgirem outros requisitos autorizadores para a aplicação dos punitive damages, tendo como embrião o enfrentamento de situações fáticas distintas que demandam a punição e consequente prevenção. Não se 
deve esquecer na formulação de qualquer parâmetro de aplicação desse instituto que o seu pilar encontra-se no objetivo de prevenir condutas altamente graves e indesejadas, geralmente marcadas por alto grau de desrespeito aos direitos alheios e vantagens do ponto de vista econômico.

\section{APLICAÇÃO DOS PUNITIVE DAMAGES NA PRÁTICA JURÍDICA BRASILEIRA}

Vistos os principais parâmetros para avaliar a incidência dos punitive damages, inarredável construir um esboço do sistema de aplicação do instituto na experiência brasileira, de modo a apontar insuficiências e pontos que podem ser incrementados.

O modelo de aplicação da indenização punitiva na experiência brasileira segue uma lógica eminentemente individual, em dissonância com o fenômeno da litigiosidade de massa e da constante transformação dos conflitos individuais em coletivos no âmbito da sociedade inserida no mundo moderno.

Embora se verifique a aplicação dos punitive damages em ações coletivas, inúmeros danos perpetrados em massa sofrem reprimenda apenas em nível individual, em proporção não compatível com a dimensão total dos danos ocasionados, o que foi constatado na pesquisa realizada na obra "punitive damages (indenização punitiva) e os danos em massa" (BONNA, 2015).

O enfoque individual na solução de conflitos no trato dos punitive damages pode enfraquecer a sua eficácia de desestímulo ante a fraca repercussão econômica do valor indenizatório, prejudicar a análise dos requisitos que o atraem e que são determinantes para a aferição do grau de censurabilidade da conduta (se o ato foi reiterado, se proporcionou 
lucro ao ofensor, se existiu elemento subjetivo que aponte para culpa grave ou dolo, etc.). Além do mais, em se tratando de danos em massa, uma visão individual afasta a possibilidade de uma proporção razoável entre a punição e o mal causado, por se tratar de demanda onde parcela expressiva das vítimas está ausente.

Outra característica da experiência brasileira é a intrínseca relação da indenização punitiva com os danos morais. Os magistrados estabelecem valor de indenização dos danos morais e o majoram o suficiente para compensá-los fundamentando na indenização punitiva. Apesar de o dano moral não se confundir com a indenização punitiva, os tribunais e juízes no Brasil têm feito uso do instituto em demandas que versem sobre dano moral.

A experiência brasileira é marcada também por ausência de fundamentação quanto aos requisitos subjetivos e objetivos, assim como sobre a gravidade da conduta que descambou na punição. Isto porque para uma necessária fundamentação das decisões judiciais deveria o magistrado se reportar diretamente à reprovabilidade da conduta, justificando a punição por meio da indenização. Deste modo, deve-se atender ao comando constitucional que obriga o magistrado a fundamentar sua decisão judicial, a teor do que dispõe o artigo 93, IX da Carta Magna de 1988.

Outro ponto relevante na experiência brasileira é a falta de distinção entre valores relativos à compensação do dano moral e os destinados à punição e dissuasão. As decisões judiciais apenas elevam o valor da indenização compensatória aludindo a indenização punitiva, mas não discriminam qual o valor suficiente para fazer frente ao prejuízo e qual se presta para punir e prevenir a conduta. Ou seja, a verba compensatória é incrementada como forma de enxertar a indenização 
punitiva em seu bojo, embora existam decisões isoladas que apliquem a indenização punitiva destacada da compensatória.

\section{CONSIDERAÇÕES FINAIS}

Partindo do pressuposto de que há uma crise de legitimidade e legalidade dos punitive damages no seio do Judiciário brasileiro, tornase inafastável a lapidação desse instituto importante para a prevenção de danos a partir do uso de requisitos objetivos e subjetivos que autorizem a sua aplicação, conferindo segurança jurídica e uma adequada fundamentação das decisões judiciais.

Conclui-se também que a experiência jurídica brasileira, após se familiarizar com a teoria dos punitive damages, deve buscar destacar o valor indenizatório que desempenha a função compensatória/reparatória do valor que satisfaz a função punitiva/preventiva. Essa técnica contribui para resolver a crise de legalidade dos punitive damages, abrindo um leque recursal par discutir apenas a verba punitiva. Foi desta forma que a experiência norte-americana incrementou a teoria dos punitive damages, pois os recursos que foram admitidos e julgados pela Suprema Corte versavam apenas sobre essa verba destinada a desempenhar uma função punitiva/pedagógica.

Espera-se que a aplicação dos punitive damages tenha um salto de qualidade no caso brasileiro a partir da observância de requisitos autorizados e do necessário destaque do valor punitivo em relação ao valor compensatório/reparatório, criando um terreno fértil para que a responsabilidade civil possa efetivar em maior grau o seu intento de prevenção de danos a partir do desestímulo de condutas indesejáveis.

\section{REFERÊNCIAS}


BONNA, Alexandre Pereira. Punitive damages (indenização punitiva) e os danos em massa. Rio de Janeiro: Lumen Juris, 2015.

BURROWS, Vanessa K. Constitutional limits on punitive damages awards: an analysis of the Supreme Court case Philip Morris USA v. Williams. USA: American Law Division, july 2007.

BANKOWSKI, Zenon et al. Rationales for precedente. In: MACCORMICK, D. Neil; SUMMERS, Robert S.; GOODHART, Arthur L. (Ed.). Interpreting precedents: a comparative study. Aldershot: Ashgate, 1997.

COOTER, Robert D. Economic analysis of punitive damages. Berkeley: Law Scholarship Repository, 1982.

DODGE, William S. The case for punitive damages in contracts. Duke Law Journal, Durham, v. 48, n. 4, fev. 1999.

DAINOW, Joseph. The civil law and common law: some poins of comparison. The American Journal of Comparative Law, Berkeley, v. 15, n. 3, p. 419-435, 1966.

HASTIE, Reid; SCHKADE, David A; PAYNE, John W. Judging corporate recklessness. In: SUNSTEIN, Cass R. et al. Punitive damages: how juries decide. Chicago: The University of Chicago Press, 2002. Chapter 5.

JAYNE, Andrew C. The impact of recent U.S. Supreme Court punitive damages jurisprudence on Oklahoma's punitive damages statute and jury instructions. Oklahoma Law Review, Oklahoma, v. 57:873, p. 873-898, 2002

KRAUSS, Michael I. Punitive damages and the Supreme Court: a tragedy in five acts. Washington, DC: Federalist Society, Aug. 2007.

MORAES, Maria Celina Bodin de. Danos à pessoa humana: uma leitura civil - constitucional dos danos morais. Rio de janeiro: Renovar, 2009. 
MCGOVERN, Francis. Punitive damages and class actions.

Louisiana: Law Review, v. 70, p. 435-462, 2010.

MENDES, Aluísio Gonçalves de Castro. Ações coletivas no direito comparado e nacional. São Paulo: Revista dos Tribunais, 2002.

MENYHARD, Attila. Punitive damages in Hungary. In: KOZIOL, Helmut; WILCOX, Vanessa. Punitive damages: common law and civil law perspectives. Vienna: Springer, 2009. v. 25.

PRIEST, George L. The problem and efforts to understand it. In: SUNSTEIN, Cass Ret al. Punitive Damages: how juries decide. Chicago: The University of Chicago Press, 2003. Chapter 1.

RUSTAD, Michael; KOENIG, Thomas. The historical continuity of punitive damages awards: reforming the tort reformers. The American University Law Review, Washington, v. 42, p. 1269-1333, 1993.

SCHREIBER, Anderson. Novos paradigmas da responsabilidade civil: da erosão dos filtros da reparação à diluição dos danos. 5. ed. São Paulo: Atlas, 2006.

SEBOK, Anthony J. Punitive damages: from myth to theory. Iowa: Iowa Law Review, 2007. v. 92

TOCQUEVILlE, Alexis de. A democracia na América: leis e costumes. 2. ed. São Paulo: Martins Fontes, 2005.

UNITED STATES SENATE. Constitution of the United States. Disponível em: < https://www.senate.gov/civics/constitution item/ constitution.htm>. Acesso em: 9 mar. 2014.

VILLARREAL, Luis Ernesto Aguirre. Integration of punitive damages into countries with a civil law system: Mexico's case. 2009. Theses (Doctor Philosophy, Sociology, Public and Social Welfare) - Tulane University Digital Library. New Orleans.

VISSCHER, Louis T. Economic analysis of punitive damages. In: KOZIOL, Helmut; WILCOX, Vanessa. Punitive damages: common law and civil law perspectives. Vienna: Springer, 2009. p. 219/236. 
VOLOKH, Alexander. Punitive damages and environmental law: rethinking the issues. Los Angeles, Califórnia: Reason Foundation, 1996. Policy Study, n. 213.

Como citar: BONNA, Alexandre Pereira; LEAL, Pastora do Socorro Teixeira. Requisitos objetivos e subjetivos dos punitive damages: critérios à aplicação no direito brasileiro. Scientia Iuris, Londrina, v. 22, n. 1, p.190-222, mar. 2018. DOI: 10.5433/2178-8189.2018v22n1p190. ISSN: 2178-8189.

Recebido em: 19/07/2017

Aprovado em: 15/11/2017 